\title{
TAKE ADVANTAGE OF THE AESTHETICS OF DIRECT SILK PAINTING IN THE PIECDESIGNSONE AS SUPPORT FOR SMALL PROJECTS IN THE KINGDOM OF SAUDI ARABIA
}

Ashjan Abdel-Fattah ABDEL-KARIM 1,2,*

${ }^{1}$ College of Science and Arts, Al-Baha University, Saudi Arabia

${ }^{2}$ Department of Art Education, Faculty of Specific Education, Assiut University, Egypt

\begin{abstract}
Textile printing is an important technical field, which can contribute significantly and directly to the interaction with the society. It can be the nucleus of small projects that contribute to the development of society and reduce the unemployment, which affects society directly. The graduates of the Department of Fashion Design and Textile Technology - Faculty of Science and Arts at AlBaha University - KSA are waiting for work opportunities in public or private schools and they don't care about establish in their own projects. Therefore, the researcher found a solution to this problem and highlighted the most important aesthetic and utilitarian values for manual printing styles and textile decoration and direct the attention of students to the interest in experimenting with the methods of textile printing and their decoration and exploitation of it to be a craft has the aesthetics, technical advantages and unique features. The students of 6th level their number was 8 were directed to produce a collection of scarves and outer garments for women made of natural and synthetic silk fabrics as one piece designs and executed using the direct drawing method on silk in order to provide unique aesthetics to guide the behaviour of student from a consumer to producer, to contribute to the development of practical and realistic solutions to create job opportunities for students after graduating. The research aims to display the aesthetics of the direct drawing on silk and the possibility of producing women's scarves and outer garments suitable for one piece designs with the possibility of opening new horizons towards the experimentation for the students of the Department of Fashion Design and Textile Technology at Al-Baha University to contribute to the provision of utilitarian ideas useful to small projects serve the society, The research is based on the descriptive approach of the theoretical framework and the experimental approach of the applied framework. The problem of research is the rareness of scientific researches in the one-piece designs of clothes and scarves of women, which carried out with the style of direct drawing on silk with study and analysis. The study resulted in the production of eight scarves and eight pieces of women's outer garments using the direct silk drawing method with dyes. The researcher recommends taking advantage of manual textile printing to serve the society.

Keywords

The Aesthetics, Silk, Painting, Support, Projects, The Kingdom Of Saudi Arabia.
\end{abstract}

\section{Introduction}

Textile printing is one of the most popular textile industries and the aesthetics. The desire to decorate fabrics with colorful drawings has existed since ancient times, as printed fabrics appeared before woven and embroidered fabrics, and these industries ranged from using the simplest equipment to using the most complex machines over thousands of years. The art of textile printing was known before history, and the link between man and textile design has existed since In ancient times, when in his primitive times he practiced this art completely innately since he mixed the furs with the blood of the animals that he used to hunt and painted them on the walls of the caves that were his shelter, and when he was unintentionally pressing the wet tree leaves on the fabric, which caught the look of the presence of traces of shapes

\footnotetext{
* Corresponding author: specedu@aun.edu.eg
} 
Those plants, then he outputs various drawings on the canvas. By studying the tapestries that were printed or drawn in Egypt in prehistoric or other eras, it became clear how man took care of his clothes and decorated them, influenced in that by the changes of the era in which he lived, whether climatic, social, political or ... etc. They have been developing until our modern era and experimentation is In the field of textile printing is one of the most important necessities that achieve the goals of this field, and experimentation comes in two directions: the first is related to the achievement of innovative aspects, and the second relates to technical aspects, and neither side is indispensable in building artistic work, as the aesthetic aspect is not achieved without controlling the necessary techniques, The technical aspects have no value without their ability to achieve special aesthetic values. Textile printing has received many academic studies from a variety of angles. However, printing one piece of women's fabrics and dress supplements such as scarves and the method of direct drawing on silk with dye has not received comprehensive academic study on the part of researchers. in Egypt. In this research, the researcher noticed that the female graduates of the Department of Fashion Design and Textile Technology at the College of Science and Arts in Al-Mandaq - Al-Baha University - Kingdom of Saudi Arabia are waiting for job opportunities in government or private schools and are not interested at all in setting up their own projects, so the researcher was keen to draw the students' attention towards the interest in experimenting with methods Printing and decoration of textiles and using this to be a craft that has aesthetics and artistic and high-tech advantages that are high and unique, so the sixth-level students, who are 8 students, were directed to produce a set of scarves and women's outerwear made of natural and artificial silk fabrics as one-piece designs executed using the method of direct drawing on silk with dye characterized by uniqueness and distinction And originality, with the aim of directing the student's behavior from a consumer student to a productive student, to contribute to developing practical and realistic solutions to find job opportunities for female students after their graduation and the possibility of establishing one of the small projects that are the infrastructure for the advancement of any society.

\section{Research problem:-}

\section{The research problem is summarized in answering the following questions:}

1. How can one benefit from the method of direct drawing on silk by dyeing and creating designs with aesthetic richness in the production of scarves and outerwear for women with designs that fit the design of a single piece, which are easily implemented with the impossibility of replicating them by other printing methods?

2. Can the different printing methods contribute to community service and the 
establishment of small projects in the Kingdom of Saudi Arabia?

\section{Theoretical framework-:}

\section{Direct drawing on silk:}

Silk painting has become a widespread art. It has also become an art reliable in its value, which can provide a profit for the artists who sell it on silk. Indeed, many silk paintings are now displayed in art galleries, and exhibitions are also organizing educational programs for designing designs on silk. The designs that can be executed on silk have no limits, just as we never find two completely identical paintings, and it may be difficult to try to repeat a piece of art that was previously executed on silk, and this is what makes it a unique and distinct art, and we find that one of the most important aspects of coloring on silk is that the pigments flow Above and through the fibers of silk fabrics, through which amazing visual effects can be obtained very simply by using special tools for this purpose, which gives it a special appeal and appearance and distinguishes it from other forms of creative art. One of the most important creative effects in silk coloring is that you get layers of color mixed well with each other instead of coloring all areas with colors of one degree, and by using the method of coloring by the method of dilute color paint, you can easily get such effects.

\section{Basic tools and supplies for direct coloring and drawing on silk:}

It must be ensured that all the necessary tools for coloring and decoration of silk are available before starting any project, as it is very important to work quickly to obtain satisfactory results.

\section{Using salt to create color effects on silk:}

This simple method gives wonderful and unexpected results through the chemical phenomenon of the absorption of salt grains of the pigment components of the colors to form dark outer lines, rings, various abstract shapes, or results like marble, but some areas actually lose their color as the colors aggregate together in different places, and in these Technology The salt is sprayed on silk decorated with colors during its wetness to obtain attractive effects, and we find that the ability of salt to absorb the water present in color is a feature that can be greatly used in this method, and the effect resulting from the use of salt depends on the degree of roughness of its grains and on its condition as all types of salt absorb Moisture from the air during its storage, so salt must be heated before use so that all the moisture evaporates from it and kept in a completely airtight container to become highly absorbent of moisture from the colors. Salt has two types of effect on color spaces, it can be used to lighten the color degree, or break up compound colors into

Its primary components are original and this depends on the properties of the colors used, and when using salt to cause effects on silk, the silk should not be wet with color to a large degree, 
otherwise the salt grains will dissolve completely, and also it will not be very dry as in this case it will give a very weak reaction and no effects may occur Not at all. The salt continues to absorb the color until it dries up completely, and as soon as the color dries, the salt must be carefully removed and we find that the area in which the effects were made

There is a widely held belief that salt always pulls the color towards the edges of the stretched silk piece, but this is not true, there is one explanation for the way in which color clouds are formed, but it depends on how the fabric is stretched and the direction of the warp and weft threads, and are there external lines defined by the insulating material such as On top of all this, the way the color is drawn depends on the amount of water and its regularity in application to the area sprayed with salt.

\section{General precautions and instructions that must be followed in the technique of direct drawing on silk:}

1. Tightening the silk from two opposite sides only helps the colors flow properly, as the color is forced to follow the direction of tension.

2. When silk is stretched and stapled on the tires, any folds, wrinkles, or wavy lines should not appear on the fabric, so as not to cause any problems and defects when drawing and coloring.

3. The more bristles and denser the brush used to mix colors, the more regular the results will be.

4. When drawing and coloring on stretched silk, the frame must be in a horizontal position so that the color does not flow.

5. The best results and effects can be obtained from placing salt particles on silk if they are placed as far apart as possible at a distance of $1-2 \mathrm{~cm}$. They must be placed on the design areas while they are wet to obtain the best results.

6. The salt should never be allowed to penetrate into the color pan, so as not to cause the color to thicken and peel off when used.

7. When using highlighter pens (jota), the identification should not be done slowly, but rather each line should be drawn with one movement and with a moderate flow, taking great care of the presence of differences in the lines so that the color does not flow through them outside the boundaries of the design.

8. The jutta defined areas should be colored after the marker has dried completely, and the coloring should be done starting from the middle, and the color in turn will spread on the silk inside the closed area, heading towards the jota line.

9. Coloring brushes must always be kept clean and never put in the color bottle so as not 
to cause damage, and diluted or mixed colors with other colors are never returned to the original bottles, rather they are kept in other airtight containers until they are used again and kept in a cool place And dark.

\section{Small projects (definition - their importance:)}

There is no unified and comprehensive definition of industries or small enterprises. This is because the concept of (small size) is considered a relative concept that differs from one country to another, and from one industry to another within the same country, and it also depends on the pattern and stage of development in the concerned country, the policy objectives drawn by the state, and the administrative systems followed. However, this topic has taken a lot of researchers' time and effort, which made one of the researchers say: It is easy to identify the small industry and manage it easily in practice, but the difficulty lies in developing a specific and general definition of the industry or small enterprises, as the criteria for defining small industries differ from country to country Other, given that in some countries the standard is based on the size of employment, total assets, the size of capital, the percentage of sales, or the quality of the technology used, but if we look at these criteria, we will find that they depend on the economic conditions of each country. In developing countries where small industries are characterized by small working capital in them, as for the scale of employment we will find it varies from one industry to another, and it is noticeable that many countries use more than one standard at once. Limit as in the European Union and the United States of America.

In the Kingdom of Saudi Arabia, small and medium enterprises play an important role in achieving economic goals, as these projects help in industrial development and help achieve fair and balanced economic growth. The competitive economy is not based on the existence of gigantic and large companies alone, but rather the presence of an attractive environment for entrepreneurial businesses and a wide and varied network of suppliers from small enterprises capable of meeting the needs of large companies. In addition, small and medium enterprises play a major role in providing job opportunities, in addition to their contribution to the total value added and their provision of goods and services, as they are able to support innovation, innovation and conduct experiments that are essential to structural change through the emergence of a group of competent and ambitious entrepreneurs. And activity. Small and medium enterprises in the Kingdom of Saudi Arabia constitute about 93\% of the total registered companies, and absorb about $27 \%$ of the total employment. The Kingdom of Saudi Arabia is one of the countries that does not have a specific definition of small industries - within the limits of researchers' knowledge - despite the reference to the need for attention. Accordingly, any attempt to define projects or small industries in the Kingdom of Saudi Arabia must be 
based on the characteristics of the Saudi industrial sector, guided by the quantitative criteria based on employment, total financing, and bearing in mind the goal of developing industries.

\section{Small projects problems and obstacles:}

Despite the economic advantages and characteristics, and the role that small industries play in the economies of any country, their performance faces some problems and obstacles, and large industries may share with them in many of these problems. However, the severity of these problems and their impact is greater and stronger on small industries. Among the most important of these problems are the following:

1. The management of some small industries is concentrated in one person (owner manager), and he is responsible for management, production, marketing, and finance.Although that person may be qualified and proficient in one of the functions and branches of management, he often lacks the technicalities. In other management functions, which makes his decisions vulnerable to failure at times and theseThe problems do not apply to the Kingdom of Saudi Arabia only, but many countries share that.

2. There are no specific programs for developing small industries, but there are some attempts in the Kingdom of Saudi Arabia that seek to develop small enterprises by building the Ministry of Industry for them and urging the Chambers of Commerce to prepare programs and seminars in which the services that small enterprises can benefit from while clarifying the problems That you face and how to address and find solutions to it.

3. The investment policy in the private sector does not differentiate between small and large industries. Rather, it provides customs exemptions and financial privileges for all industrial sectors, regardless of the size of the industry. It follows from this situation that the investment promotion system helps to bias investments towards large industries rather than small industries.

4. Most of the small industries tend towards tradition in establishing enterprises without diversity. This has led to concentration in certain areas without the other without taking into account the absorptive capacity of the local and regional market.

5. Many small enterprises operate independently in production rather than integration with large enterprises. This situation has resulted in the failure to take advantage of the raw materials provided by these industries, the failure to exploit all production capacity, the increase in marketing and transportation costs, and the failure to benefit from the expertise and capabilities of large companies., This situation has hurt the small 
enterprises, exposing them to unequal competitors.

\section{Results:}

1. Producing eight innovative scarves and eight pieces of outerwear for women, using the technique of direct drawing on silk with dye, achieving aesthetic richness, ease of implementation and beauty of shape.

2. Enriching the plastic value of the one-piece designs of printed ladies' garments.

3. Opening new horizons for small projects for female students after their graduation, with a low cost and an adequate and fast financial return.

4. The possibility of benefiting from the methods of textile printing and decoration in support of small projects and community service.

5. The link between the field of textile printing and decoration and the field of fashion design to achieve the highest utilization of products to be a nucleus for small female students 'projects, which in turn contribute to the development of society.

\section{Recommendations:}

1. Preparing more specialized studies that are concerned with artistic and technical development in various fields, especially the field of textile decoration and printing.

2. Unleashing innovative ideas that are developed at the lowest possible costs, thus revealing many unexpected and more creative ways, and even combining the various advantages of different methods.

3. The possibility of using the designs found in the research and employing them as a small project due to the simplicity of the tools used and their low costs in order to eliminate unemployment.

4. Helping young girls to create job opportunities for them in small projects with economic and easy-to-learn ideas.

5. The necessity of mixing the different technical fields, not separating them and trying to invest in the integrated vision to enrich the printed products.

6. Training on various methods and methods in implementing printed textiles to achieve the highest levels of distinguished production in the easiest and fastest way.

\section{References:}

1. Ahmed Al-Gendy: "Promoting the Free Labor Thought (a joint study between the Social Fund for Development and the University Institutions) The Social Fund for Development, Cairo - pp. 149 - 2008 AD.

2. Ahmed Abdel Qader Muhammad - Saud Fayyad Al-Fayyad: "Small industries in the Kingdom of Saudi Arabia, the role and obstacles," Industrial Cooperation, Volume Thirteenth, 
Issue Fifty, pp. 6:29, October 1992.

3. Ihab Fadel Abu Moussa - Jehan Abdul Hamid Nawar: "A proposed educational program to prepare and implement a" mantle "using computer software to serve small and medium industries, Home Economics Research Bulletin - University of Menoufia, Volume 12 - Issue (4) - December 2002.

4. Hammoud Al-Saad Al-Ibrahim: "Productivity Experience in Small Industrial Companies", Riyadh Trade, 1990.

5. Hanan Al-Tantawi: "Investing the aesthetics of the anthology of marine creatures in new publications for a single piece of women's fashion by removing the printing method", unpublished PhD thesis, Faculty of Art Education, Helwan University, Cairo, 2005.

6. Dar Al-Shamal Edition, Publishing and Distribution: "The Art of Painting by Silk", second edition, 2005

7.- Suhair Mahmoud and Othman: "The National Character and Design of Textile Printing", The Fifth Scientific Conference, The Second Axis Development and Production, College of Applied Arts - Helwan University, from April 11 to 10, 1995.

8. Afaf Ahmad Omran: "Creating creative fields by combining the two styles of stenciling and thermal screen printing," Journal of Research in Art and Art Education, Faculty of Art Education, Helwan University, Volume III, Issue III, July 2001.

9. Ali Al-Salma: "Lecture on Small Establishments in the Kingdom of Saudi Arabia", Chamber of Commerce and Industry in the Eastern Region, Dammam, 2001.

10. Inayat Al-Mahdi: "The New in the Art of Painting by Al-Harir", Dar Al-Talal for Publishing and Distribution, 1999.

11. Mustafa Irshad, Ali Al-Sayed Qotb: "Design and Manual Methods in Textile Decoration", Cairo, pp. 3 - 47,

12. Mona Ayed- Sanadar Abbas Al-Arifi: "Introduction to Fabric Design and Printing", Ministry of Higher Education and Scientific Research, Technical Institutes Authority, Boys Institute for First Grades, 1990

13. The Ministry of Foreign Trade: "Study on the Israeli Definition of Micro, Small and Medium Enterprises in Egypt”, July 2002.

14. Ministry of Industry and Electricity: "A guide to Saudi factories produced at the end of 1409 AH (1989 CE)", Riyadh, Kingdom of Saudi Arabia.

15. Ray and Hurchinson, Op. Cit., P. 1

16. SME Advisor Arabia

17. Dalia A. ABDELAZIZ, Abeer F. Ahmed ALI, PLASTIC POSSIBILITIES OF 
TAKE ADVANTAGE OF THE AESTHETICS OF DIRECT SILK PAINTING IN THE PIECDESIGNSONE AS SUPPORT FOR SMALL PROJECTS IN THE KINGDOM OF SAUDI ARABIA

CERAMICS AND METALS AS AN INTRODUCTION TO CREATE CONTEMPORARY JEWELRY, International Journal of Design and Fashion Studies, Vol. 2, No. 1, 2019, pp. 1-3. 18. Rabab Ahmad AL-RIFAI, POLITICAL AND SOCIAL INFLUENCES ON FASHION IN 1930S, International Journal of Design and Fashion Studies, Vol. 2, No. 1, 2019, pp. 4-11.

Received: September 11, 2019

Accepted: November 30, 2019 